\title{
The Effect of Human Resource Skills on Risk Management in AL-Manhal Contracting EST
}

\author{
Mohammed Mutasim Al Dabbas \\ Email: engmohammeddabbas89@yahoo.com \\ Jordan \\ Shaker Jaralla Alkshali \\ The world Islamic Sciences \& Education University \\ Email: drshaker55@yahoo.com \\ Jordan
}

\section{ABSTRACT}

The study aimed to examine the effect of human resource skills (technical skills, intellectual skills, and communication skills) on risk management (risk identification, risk transfer, and risk reduction) in AL-Manhal Contracting EST in Jordan. The study was conducted on a sample of (226) employees in the company. The study used a descriptive and analytical method. The results indicated that there are high levels of human resource skills, preceded by technical skills, then communication skills, and finally intellectual skills. As for the dimensions of risk management, the results indicated that there is a high level of risk identification, while risk transfer and risk reduction came at medium levels. The results showed that there is a significant effect of human resource skills on risk management.

\section{KEYWORDS: Human Resource Skills, Risk Management, AL-Manhal Contracting EST, Jordan.}

\section{Introduction}

Construction projects are considered the riskiest among the industries due to its unique nature, where risk management in construction projects has become an essential requirement following the modern trends in the preservation of the resources of the state and control performance, and the need to work using modern techniques in the implementation of construction projects for the completion of projects in the shortest possible time and less cost without the extra bulk (Khalil, Saleh \& Ghaib, 2016). Risk management is represented as an approach or introduction to deal with the construction projects and this includes a series of steps which integrate of scientific facts and identify risks, transfer risk and reduce risk (Florio \& Leoni, 2017). Construction projects encounter many risks that might affect their performance of the obligation in terms of time, cost and quality that have been determined for it. Construction projects have its special nature that might be exposed to many risks where it is designed in a dynamic environment that frequently changes and it is linked to multiple parties such as the owner, consultant, contractor, project manager and staff, following this the process of risk management of construction projects is important for the success of projects based on the human resource skills and experience (Al-Othman, 2017). The progress and prosperity of construction companies depends on their acquisition of human resource with intellectual and technical skills as well as communication skills. Companies strive to make progress by relying on the mental cognition they own for targeting the goals they seek. Addressing future risks and challenges requires highly skilled and capable human resources. Because construction projects operate within a dynamic environment that is variable, it invokes the procedures to evaluate the competitive capacity of the sector of construction through the development of skills and human resource to face and manage the risks they face (Zeituny, 2014). Companies currently seek to develop its human capital, Because of the increasing importance of the skills possessed by employees as a strategic resource to achieve competitive advantage and it is one of the most important assets that the company own. Human capital is a source of wealth based on individual's experience, knowledge and expertise (Zawawi Khadija, 2017).

\section{Theoretical Framework}

\subsection{Human Resource Skills}

Human skills are not fixed but variable depending on business needs, which vary according to persons, place, and time. This means that human skills have many definitions, types, and characteristics. Human resources working in organizations have a set of basic skills that help them with the execution of their tasks. Researchers couldn't determine a precise definition of the concept of human resources because there are many points of view and skills; it's the experience and capabilities that the human resource used in the implementation of the activities and tasks entrusted to it (Hunt \& Schermerhorn, 2002, 15). As it's known as the natural talent acquired that helps the human resource to perform tasks and activities assigned to them whether on the physical or mental 
and there are a set of technical, intellectual, and communicative skills possessed by the human resources workforce that characterized it from other organizations which work within the same sector, human resources use their scientific and applied knowledge to choose the methods. (Hussein, 2018).

Human skills depend on the professional practice and its connection to the communities and the organization that represents disjunction and professional practice realized that these human skills overlapping may use one without the other and must have the ability to determine the appropriate method to use in accordance with the position or the problem which deals with it and with the level of the customer, according to the organization and its goals and the quality of their services (Groh, Krishnan, McKenzie \& Vishwanath, 2016). Human skills aim to achieve the process of assistance and make a difference through different stages of professional practice.

Human skills are based on aspects of professional process and clear human aspects that interact with each other during practice situations (Bakay \& Kirkit, 2017). Human skills are a set of knowledge, work abilities, and behaviors organized for a particular purpose and specific situations and they are the ability of an individual to translate knowledge into action so that desired and expected outcomes can be achieved (Almagrabi, 2019, 130). It was defined as the skills that provide the individual with a fundamental rule of general information, which is often the idea and the theory, which can form the foundation that supports it in the performance of work with some adaptation, to suit the needs of the work. Particular works can lengthen the adaptation period more than others according to the nature of the tasks (Jawad, 2010, 46) it is the skills that provide information to the theory and practice to suit the nature of the skills required for the work and the kind of skills required to perform the work.

Human skills are not fixed but variable depending on business needs, which vary according to a person's time and Place (Mohammed, 2011, 130). The skills of Human Resource are a set of abilities innate and acquired need products to ensure the performance of effective and subject to evolution and development (Hegazy \& Souad, 2013, 81).

Human resource skills aim to raise the level of productivity and quality of the organization and contribute to the economy in costs and minimize mistakes in the long run than it alleviates costs and improve the effectiveness of the working methods and raise the confidence level and this leads to adapt working with variables in the internal and external environment of the organization, help in reducing accidents at work and reduce the need of close supervision (Rakam, 2014). To measure human resource skills, the study was based on a three-dimensional scale that would be briefly addressed.

1. Technical Skills: they are the skills related to the technical aspect that reflects the human resource capacity to use the tools, equipment, technology, and techniques and employ them to simplify the work they do (Hussein, 2018). They are also the skills resulting from the knowledge and experience acquired by employees in their area of competence, which reflect the majority of those who perform their tasks with skill and excellence (Al-Nuaimi, 2008, 39). It is important to provide these skills at the lower administrative levels especially to managers in the staff level because their work is often associated with technical aspects of the performance of employees, these skills must be available to the managers who are in direct contact with them and follow the achievements (Hmoud \& Al-Lawzi, 2008, May 31).

2. Intellectual Skills: these skills indicate the human resource capacity to think and devise solutions to problems that the company could face them at work, as well as its role in rationalization decision-making processes to implement the activities and tasks assigned to them and these tasks are reflected by the employee's ability to perform tasks using analytical thinking (Al-Nuaimi, 2008, 40), made a clear vision about the topics and problems that will be addressed based on perceptions of the holistic and the ability to address the problems and circumstances surrounding the organization (Ahmed \& Mohammed, 2012).

3. Communication Skills: it is the process of expressing the wishes and thoughts of employees in an effective manner and this represents the first half of the process of communication they need to activate the relationship with the buyers, as for the second half it would be listening and understanding others, communication is a dynamic process and it is the aim of all organizations. Through communication, the organization could standardize its activities toward the planned goal and transferring information between the employees. Poor communication between the staff is the root of many problems within the organization (Mathew, 2009).

\subsection{Risk Management}

The range of administrative activities of the organization which helps in the prediction of specifying and evaluating the risks and control these risks by developing their management strategies and this will limit the negative impacts and will avoid and reduce them to an acceptable level (Khalil et al., 2016). Risks that face projects are the determinants that hinder the work of those projects and their effectiveness and efficiency and thus reflected negatively on its performance and the extent of its success, which requires them to manage effective follow up of proper planning and efficient oversight of the overall substantive to counter those risks by predicting what will happen in the future. Risks are part of the business so there is no high return without risk. Risk management importance increases because of the nature of the projects some projects are unique which makes a lot of projects face failure with high probability (Khader \& Yousef, 2018). The term risk means the possibility of being hurt. Risk 
management is the art and science which is concerned with determining the procedures followed by the organization to face the risks by identifying risks and putting strategies to dispose of or mitigate the negative impact without any increase in costs. The risk management insurance system aims to ensure the achievement of the desired goals and it is an investment process that aims to maximize the outcomes, increase success probability and decrease failure probability (Dofran, 1997).

Risk management is a continuous management process that predicts the potential risks by monitoring environmental variables, internal and external-generated risks, mobilize available resources and possibilities to be prepared to deal with the risk as much as possible of efficiency and effectiveness to achieve the lowest possible harm to the organization environment and employees and ensuring reversal to normalcy ASAP. Identifying the causes to conclude results to prevent its occurrence or to improve the ways of dealing with them in the future (Asali, 2009, 3). Risk management is considered as the organization's ability to deal with disasters in order to reduce threats and life losses and property damage with the continuation of its activities and re-balance the system in less time and start its activity again (Souusha, 2019). In this study, the following three dimensions of risk management measurement were adopted.

1. Risk Identification: is the process of determining what the organization wants to do in its system of risk management, in order to get the maximum benefit from risk management, and it's an essential step to identify risks (AbdelMoneim, Kasib \& Kashif, 2008, 6). In other words, the organization reaching its goals by avoiding the losses associated with the risks and achieve its desired goals, the process of risk identification depends on the definition of risk approach to ensure the identification of all the activities of the organization, as well as define risks that are associated with the target (Puspasari \& Syaifullah, arimbi 2019).

Identifying risks in construction projects is done at the stage of the feasibility study that precedes the start of the project and this stage is the first stage and it's the most important one in risk management because of its importance in determining the merits of the problem facing the project and addressing them. Identifying risks in the project by interviewing the main members of the project staff and discuss their expected hazards, use their personal experience in determining risk and similar risks that occurred in previous projects (Perry, 2000).

2. Risk Transfer: is a term used in risk management project and it's one of the strategies of dealing with risk, whereby the project team transfer or transform the impact of threats and risks of the project to other projects, where the management handle those risks and develop suitable strategies for dealing with risks instead of the organization responding to it (Car \& Taha, 2010). The process of transferring risk has a set of procedures and measures undertaken by the company after the occurrence of risk; abandon goals that might generate risk. Transferring risks requires removing some of the threats and negative impact or the whole with the responsibility of responding to those risks to a third party. It simply gives responsibility to a third party to manage those risks without deleting it. Risk transfer tools vary and it might include the use of insurance, performance guarantees, guarantees, and others (Tata'a \& Samaya, 2014).

3. Risk Reduction: is the process of reducing the probability and effectiveness of a risk to make within the limits, to take early action to reduce the possibility and occurrence of risks on the project is often more effective than trying to repair the damage after the occurrence of those risks as each project has its own circumstances, so risk reduction will be according to the circumstances of each individual project (AL-Bahar \& Grandall, 1990). Risk reduction is usually done through actions such as training the staff to sensitize them about the project to increase their awareness of potential risks happening, appropriate planning to execute the project following simple procedures, do more tests and allocate resource that is qualified scientifically and technically to increase coordination and communication between the project employees. Applying preventive measures is the most effective way to reduce risks (Tata'a \& Samaya, 2014).

\section{Literature Review}

In a study conducted by Dianah, Fitiri \& Ibrahim (2019) indicated that the internal audit system was effective in identifying the sources of risk and can have a negative impact in performance, particularly in terms of the reliability of financial reporting, asset security, effectiveness, and efficiency and compliance with regulations. The study found that internal audit was effective in identifying the sources of risks that can have a negative impact on performance. There are risks related to human resources issues, communication issues, cooperation, and ethics that can impede activities in the Organization. Firmenich (2017) study shown that there are three benefits of the project manager managing the risks: choosing necessary steps that will be performed to manage the risks of the project, determine the number and type of persons involved in each step and choose the combination of methods applied throughout the process. These options allow the project manager to select the best solution for each building project, despite cost pressures and problems of efficiency possible between those who run the risk management of the project. On the other hand, Jaguda and Wojcik (2019) study showed that integrating risk management into the organization's strategic process was an invaluable asset. The importance of risk management is often ignored, yet the integration of risk analysis can be an important asset for sustainable business. In order to establish a risk management process, companies must identify a set of objectives and gain management and staff support. Risk management must be 


\section{CCenter for Promoting Education and Research (CPER) USA}

www.cpernet.org

established and integrated into the current corporate structure. There should be integration between risks and the current responsibilities and legislation of the government and this should be done in accordance with existing capabilities and regulations. Companies need to be supported by a plan that reaches all staff within the organization to follow a safe and effective practice that reflect current risk reduction techniques. Suhadak and Rahayu, (2018) study showed that there is a trace of the capital in risk management and risk management has a positive effect on performance, but risk management has no effect on profitability and that profitability has a positive effect on performance, but capital has a negative impact on profitability. On the other hand, profitability has a negative impact on capital and that performance has a positive effect on the capital, while the capital has no effect on performance.

Maciel, Pardini, and Monteiro's (2017) study showed that there is a possibility of inference in risk factors relating to the management of social risks in two areas and they are internal and external risk assuming an equal level of importance. This means that the internal and external factors must be taken equally with risk management analysis, which requires an effective and secured internal structure to manage effective foreign management. Indicators have also shown the importance of adopting business policies, the structure of operations deployed, human resources, and accident prevention. It is important to note that social risk management varies between organizations and in different contexts. The study that was conducted by Javani and Rwelamila (2016) explained that risk management is important as a knowledge base and risk reduction in projects. They also pointed at the importance of knowledge sharing and knowledge bases in risk management, it turns out that, despite the emphasis on the importance of risk management experts of the projects was not dealing with it at the required level. The study showed that organizations do a full evaluation of risks when doing a project, but mostly there is no systematic approach to risk management in organizations. Cameron, Ashwell, Connor, Duncan, Mackay, and Naqvi (2019) study showed the importance of organizations understanding that strategic expansion of integrated learning is likely to be accompanied by huge risks for stakeholders and there is a series of risk management practices in response to five major risks in programs to evaluate integrated learning that is applied by stakeholders in the work to improve the risk management framework in their organizations, improving legal literacy. It turns out that there are four topics: study balance, collaboration, Relationship Management, and resources which has been characterized as guidelines for stakeholders in risk management.

\section{Hypotheses}

H1: There is an impact of human resource skills on risk management in AL-Manhal Contracting EST.

H2: There is an impact of human resource skills on risk identification in AL-Manhal Contracting EST.

H3: There is an impact of human resource skills on risk transfer in AL-Manhal Contracting EST.

H4: There is an impact of human resource skills on risk reduction in AL-Manhal Contracting EST.

\section{Method}

\subsection{Sample}

The study population consisted of all the employees of AL-Manhal Contracting EST, whose number was (800) employees. The researchers adopted the questionnaire to collect data from a random sample of size (260) employees according to the sample table (Sekaran \& Bougie, 2012), where (260) questionnaire was distributed. After the distribution, the (226) questionnaire was retrieved, which is valid for analysis, and it constitutes (87\%) of the sample size.

\subsection{Measurement}

To measure human resource skills (the dependent variable), the scale used in the study (Hussein, 2018) was used, which is composed of three dimensions, namely: technical skills, intellectual skills, and communication skills. To measure risk management (the dependent variable), a scale consisting of three dimensions was used in the study (Javani \& Rwelamila, 2016), namely: risk identification, risk transfer, and risk reduction Table (1).

The answer to the two scales was determined according to the five-point scale. Strongly agree (5) point and strongly disagree (1) point. The reliability of the measures was tested and it was found that all of them exceeded (0.70), indicating their stability.

\section{Results}

Table (1) Reliability and descriptive analysis

\begin{tabular}{|c|c|c|c|c|c|c|c|c|c|c|c|c|}
\hline Variable & & Dimension & Items & Alpha & Mean & Std. & 1 & 2 & 3 & 4 & 5 & 6 \\
\hline \multirow{3}{*}{ HR Skills } & 1 & Technical Skills & 5 & 0.761 & 3.912 & 0.727 & & & & & & \\
\hline & 2 & Intellectual Skills & 5 & 0.877 & 3.714 & 0.841 & 0.706 & & & & & \\
\hline & 3 & Communication Skills & 5 & 0.808 & 3.861 & 0.705 & 0.560 & 0.622 & & & & \\
\hline \multirow{3}{*}{$\begin{array}{c}\text { Risk } \\
\text { Management }\end{array}$} & 4 & Risk Identification & 5 & 0.821 & 3.681 & 0.859 & 0.576 & 0.638 & 0.585 & & & \\
\hline & 5 & Risk Transfer & 5 & 0.854 & 3.585 & 0.891 & 0.545 & 0.667 & 0.551 & 0.713 & & \\
\hline & 6 & Risk Reduction & 5 & 0.899 & 3.642 & 0.913 & 0.653 & 0.680 & 0.662 & 0.640 & 0.767 & \\
\hline
\end{tabular}




\section{CCenter for Promoting Education and Research (CPER) USA}

WWW.cpernet.org

Table (1) refers to the results of Cronbach's Alpha test items of this dimension was (3.912), and less than that for for the items of the study tool, where the test results indicated communication skills with mean (3.8837), followed by degrees of stability that exceeded the permissible limits (0.70) intellectual skills with a mean (3.714). About the dimensions for being approved for statistical analysis (Sekaran \& Bougie, of risk management, it was found that the risk identification 2012). The table also shows the results of the descriptive was with the highest mean $(3,681)$, at high levels, and in the analysis (mean and the standard deviation) of the study items, second degree the risk reduction with mean $(3,642)$, at medium as it was found that the employees of the company possess a levels, and finally, risk transfer with mean $(3,585)$, at medium high degree of technical skills, as the value of the mean for the levels.

H1: There is impact of human resource skills on risk management in AL-Manhal Contracting EST. Table (2) Impact of human resource skills on risk management

\begin{tabular}{|c|c|c|c|c|}
\hline Dimension & B & Beta & T & Sig. \\
\hline Technical Skills & 0.224 & 0.202 & 2.318 & 0.022 \\
\hline Intellectual Skills & 0.384 & 0.400 & 4.340 & 0.000 \\
\hline Communication Skills & 0.341 & 0.298 & 3.779 & 0.000 \\
\hline $\mathrm{R}=0.787 \quad \mathrm{R}^{2}=0.619$ & $\mathrm{~F}=56.928$ & \multicolumn{2}{c|}{ Sig. $=0.000$} \\
\hline
\end{tabular}

Table (2) shows the results of multiple regression resources skills in risk management. The transactional table analysis of the impact of human resources skills on risk management in AL-Manhal Contracting EST, where the value of the correlation coefficient $\mathrm{R}(0.787)$ indicates the existence of a relationship between human resource skills and risk management. While the value of R2 was (0.619), this means that human resources skills explained $(61.9 \%)$ of the variance in risk management, and the value of $\mathrm{F}(56.928)$ at the level of Sig. (0.000), which indicates a significant impact of human hypothesis can be accepted.

H2: There is impact of human resource skills on risk identification in AL-Manhal Contracting EST.

Table (3) Impact of human resource skills on risk identification

\begin{tabular}{|c|c|c|c|c|}
\hline $\mathrm{R}$ & $\mathrm{R}^{2}$ & $\mathrm{~B}$ & $\mathrm{~F}$ & Sig. \\
\hline 0.692 & 0.479 & 0.902 & 98.180 & 0.000 \\
\hline
\end{tabular}

Table (3) shows the results of the simple regression of the variance in identifying risks. The value of $F$ was (98.180) and effect of human resources skills on risk identification. It was the level of significance was (Sig. $=0.000$ ), which indicates the found that there is a relationship between the two variables, existence of a statistically significant effect of the skills of where the value of the correlation coefficient was $(\mathrm{R}=0.692)$ human resources on risk identification in AL-Manhal while the value of $\mathrm{R}^{2}$ was (0.479), and this means that the Contracting EST. So the second hypothesis can be accepted human resource skills it interpreted an amount (47.9\%) of the

H3: There is impact of human resource skills on risk transfer in AL-Manhal Contracting EST.

Table (4) Impact of human resource skills on risk transfer

\begin{tabular}{|c|c|c|c|c|}
\hline $\mathrm{R}$ & $\mathrm{R}^{2}$ & $\mathrm{~B}$ & $\mathrm{~F}$ & Sig. \\
\hline 0.680 & 0.463 & 0.920 & 92.215 & 0.000 \\
\hline
\end{tabular}

Table (4) shows the results of the simple regression of the variance in risk transfer. The value of $F$ was (92.215) with the effect of human resources skills on transferring risks. It a significant level (Sig.=0.000), indicating the existence of a was found that there is a relationship between the two statistically significant effect of human resources skills on risk variables, where the value of the correlation coefficient $\mathrm{R}$ was transfer in AL-Manhal Contracting EST. In light of the results (0.680), while the value of $\mathrm{R}^{2}$ was (0.463). This means that of the analysis, the third hypothesis can be accepted. human resources skills interpreted the amount of $(46.3 \%)$ of

H4: There is impact of human resource skills on risk reduction in AL-Manhal Contracting EST.

Table (5) Impact of human resource skills on risk reduction

\begin{tabular}{|c|c|c|c|c|}
\hline $\mathrm{R}$ & $\mathrm{R}^{2}$ & $\mathrm{~B}$ & $\mathrm{~F}$ & Sig. \\
\hline 0.765 & 0.586 & 1.060 & 151.333 & 0.000 \\
\hline
\end{tabular}


Table (5) shows the results of a simple regression of the effect of human resources skills on risk reduction. It was found that there is a relationship between the two variables, as the value of the correlation coefficient $R$ was $(0.765)$ while the value of R2 was (0.586), which means that human resource skills were interpreted an amount $(58.6 \%)$ of the variance in risk reduction. The value of $\mathrm{F}(151,333)$ was Sig. (0.000), which indicates a statistically significant effect of human resources skills on reducing risks for AL-Manhal Contracting EST. Therefore, the fourth hypothesis can be accepted.

\section{Discussion}

The study aimed to examine the effect of human resources skills on risk management in AL-Manhal Contracting EST. The results indicated that there are high levels of human resource skills for the employees of the company, especially about technical skills, as the company has employees with high technical skills capable of using and employing technological equipment, as they possess high experience in their field of specialization, which is positively reflected in their carrying out their work tasks distinctively. The company's employees also have high communication skills that enabled them to express their desires and convey their ideas, in addition to having the skills to listen to their colleagues, share information and discuss ideas with them. The company also possesses human resources with high intellectual skills that enable it to devise solutions to the problems that the company may face, which is positively reflected in appropriate decision-making, as employees have analytical capabilities and comprehensive perceptions to meet the exceptional circumstances facing them. It was found that there is a high level of risk identification in AL-Manhal Contracting EST, as the process of identifying risks in construction and construction projects begins in the feasibility study stage that precedes the start of the project. This stage is considered the first and most important stage in risk management because of its great importance in determining the merits of the problem facing, the project thus shows how to address it. On the other hand, the levels of risk transfer and risk reduction came at medium levels, as the human resources in the company possess the necessary skills to identify risks with their expertise, but their capabilities to transfer or reduce these risks are modest, and the reason for this may be that the transfer of risk on the other hand, a decision is required from the higher management.

The results showed that there is a significant impact of human resource skills on risk management, and intellectual skills came at the forefront of this effect, which relates to the ability of employees to elicit solutions to problems through logical and proactive thinking in dealing with problems, choosing appropriate solutions to them and rationalizing the decision-making process. In addition to that, communication skills had a clear effect and this result indicates the importance of human interaction, as the more employees can express their ideas, express their opinions and what they feel, ask for help and support of their colleagues in discussing their ideas and building on the ideas of others, the more this helps in dealing with risks and managing them efficiently. As for technical skills, their impact was also significant on risk management due to their great association with the nature of the company's work. The employee's possession of technical expertise enabled them to anticipate potential risks and determine appropriate ways to deal with them before they occur.

\section{References}

Abdel-Moneim, Atef, Kasib, Sayed, \& Kashif, Mohamed Mahmoud (2008). Risk assessment and management. Cairo, Egypt, Center for Graduate Development and Research.

Ahmed, Maysoon Abdullah, \& Muhammad, Yana Manaf (2012). Leadership patterns and their role in developing the skills of workers. An exploratory study of the opinions of a sample of the leaders of departments and workers in the district of Nineveh Electricity Network. Al-Rafidain Development Journal, 34(9), 201-232.

Al-Bahar, J, \& Crandall, K. (1990). Systematic risk management approach for construction projects. Journal of Construction Engineering and Management, 116(3), 533-546. doi.org/10.1061/(ASCE)0733-9364(1990)116:3(533).

Almagrabi, Abdel Hamid Abdel Fattah (2019). Recent trends in human resource management studies and practices. Egypt, Cairo, The Modern Library for Publication and Distribution.

Al-Nuaimi, Salah Abdul-Qadir (2008). Leading director and strategic thinker. Jordan, Amman: Ithraa for Publication and Distribution.

Al-Othman, Abeer Abdullah Mohammed (2017). The impact of construction project risk management on performance: A field study in the General Secretariat of Endowments, Ministry of Endowments - State of Kuwait. PhD thesis, University of Islamic Sciences, College of Graduate Studies, Amman, Jordan.

Asali, Noureddine (2009). Conflict management and its impact on job placement for workers. A case study of Al-Hodna Mills Corporation, Al-Missilia state, Master Thesis, University of Algeria, Faculty of Economic Sciences.

Bakay, Mawlud, \& Kirkit, Omar (2017). Human resources and management information technology skills. Journal of Development and Human Resource Management, 2(5), 56-86. 
Cameron, Craig, Ashwell, Janine, Connor, Melissa, Duncan, Mary, Mackay, Will, \& Naqvi, Jeff (2019). Managing risks in work-integrated learning programmes: A cross-institutional collaboration. Higher Education, Skills and Work-Based Learning, DOI 10.1108/HESWBL-05-2019-0072

Car, V., \& Taha, j. H. M. (2010). A proposal for construction project risk assessment using fuzzy logic. Construction Management and Economics, 18(4), 491-500, doi.org/10.1080/01446190050024905.

Dianah, Azimah, Fitria, Ana, \& Ibrahim, Azharsyah (2019). Internal control system of the state Islamic Universities in Indonesia: Studying the effectiveness and risk management. Share Jurnal Economim Keuangm Islam, 1(8), 68- 89, DOI:10.22373/share. v8i1.4910

Dofran, M. S. (1997). Introduction to risk management and insurance. Prntice Hall.

Firmenich, Jennifer (2017). Customisable framework for project risk management. Construction Innovation, 17(1), 68-89. DOI 10.1108/CI-04-2015-0022.

Florio, C., \& Leoni, G. (2017). Enterprise risk management and firm performance: The Italian case. The British Accounting Review, (49), 56-74, doi.org/10.1016/j.bar.2016.08.003.

Groh, M., Krishnan, N., McKenzie, D., \& Vishwanath, T. (2016). The impact of soft skills training on female youth employment: Evidence from a randomized experiment in Jordan. Journal of Labor \& Development, 5(9), 1-23, DOI 10.1186/s40175-016-0055-9.

Hegazy, Ismail, \& Maalim, Souad (2013). Human resources go through skills. Jordan, Amman: Osama House for Publishing and Distribution.

Hmoud, Khudair Kazem \& Al-Lawzi, Musa Salama (2008). Principles of business administration. Jordan, Amman: Ithraa House for Publishing and Distribution.

Hunt, G., \& Schermerhorn, S. (2002). Comportment human organization (2ed ed.). France, Paris: editions Imprimé au Canada.

Hussein, Hussein Walid (2018). The role of information technology on enhancing customer insight through human resources skills - An exploratory study of the views of a sample of Iraqi Asiacell Communications Company Employees. Journal of Administration and Economics, (117), 154-166.

Jagoda, Kalinga, \& Wojcik, Patrick (2019). Implementation of risk management and corporate sustainability in the Canadian oil and gas industry: An evolutionary perspective. Accounting Research Journal, 32(3), 381-398. DOI 10.1108/ARJ-052016-0053.

Javani, Blessing, \& Rwelamila, Pantaleo Mutajwaa Daniel (2016). Risk management in IT projects - a case of the South African public sector. International Journal of Managing Projects in Business, 9(2), 389-413.DOI 10.1108/IJMPB-072015-0055

Jawad, Shawqi Naji (2010). Workers management a holistic perspective. Jordan, Amman: Dar Al-Hamed Publish and Distribution.

Khader, Tamam Salman, \& Youssef, Marwa Badr Zia (2018). The effect of risk management on project performance. An applied study of the General Company for Agricultural Equipment Buildings project, one of the Iraqi Ministry of Agriculture formations. Journal of the Baghdad College of University Economics, (56), 145-164.

Khalil, Tariq Abdul Majeed, Saleh, Salah Abdul Hamid, \& Ghaib, Heba Omar Al-Ela (2016). The use of geographic information systems in managing construction projects. Engineering and Technology Journal, 34(7), 209-218.

Maciel, Ana Carolina de Moura, Pardini, Daniel Jardim, \& Monteiro, Plínio Rafael Reis (2017). Social risk management: Structuring, validation, and testing of a survey in the mining industry. Social Responsibility Journal, 15(8), 992-1007. DOI 10.1108/SRJ-11-2017-0246

Mathew, P. (2009). The Impact of soft skill training. https://articlesbase.com/Management articles.

Mohamed, Mohamed Abdel Fattah (2011). Contemporary theoretical trends to organize models and theories of technical skills. Egypt, Alexandria, The modern university office.

Perry, J. (2000). The association for project management (formerly the association of project managers). The University of Birmingham.

Rakam, Linda (2014). Lessons in the foundations of human resources management supported by applied cases. Department of Management Sciences, Faculty of Economic and Business Sciences, University of Farhat Abbas, Setif.

Souusha, Hamza (2019). International crisis management. Symposium Journal of Legal Studies, (23), 84-110. 
Suhadak, Erna Sari, \& Rahayu, Sri Mangesti (2018). The effects of Tier-1 capital, risk management, and profitability on performance of Indonesian Commercial Banks. International Journal of Law and Management, 60(5), 1074-1086. DOI 10.1108/IJLMA-05-2017-0109

Tata'a, Batoul, \& Samaya, Bushra (2014). Managing risks in textile industries in Halep using the hierarchical analysis technique. Al-Quds Open University Journal for Research and Studies, (34), 343-365.

Zawawi, Khalsa, \& Bin Khadija, Moncef (2017). The role of e-learning in developing the intellectual capital of economic institutions - a field study for some institutions in Setif -. Economic Insights Journal, 7(2), 236-248.

Zeituny, Samia (2014). The impact of administrative leadership styles on the development of skills in human resources. Journal of Law and Humanities, 1915-159-1968. 